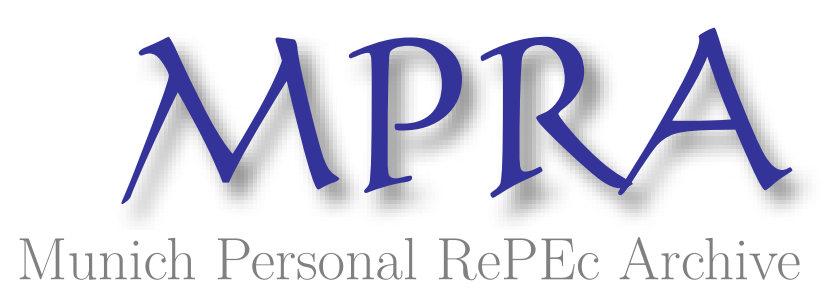

\title{
Choosing a retirement income strategy: a new evaluation framework
}

Pfau, Wade Donald

1 June 2012

Online at https://mpra.ub.uni-muenchen.de/39169/

MPRA Paper No. 39169, posted 01 Jun 2012 13:08 UTC 


\title{
Choosing a Retirement Income Strategy: A New Evaluation Framework
}

\author{
by \\ Wade D. Pfau \\ Associate Professor \\ National Graduate Institute for Policy Studies (GRIPS) \\ 7-22-1 Roppongi, Minato-ku, Tokyo 106-8677 Japan \\ Email: wpfau@grips.ac.jp \\ phone: 81-3-6439-6225
}

\begin{abstract}
This article presents the initial stages of a new evaluation framework for choosing among retirement income strategies. The investigation includes eight retirement income strategies: constant inflation-adjusted withdrawal amounts, a constant withdrawal percentage of remaining assets, a withdrawal percentage based on remaining life expectancy, a more aggressive hybrid withdrawal percentage, inflation-adjusted and fixed single premium immediate annuities, a variable annuity with a guaranteed living withdrawal benefit rider, and a strategy which annuitizes the flooring level to meet basic needs and uses the hybrid withdrawal percentage for remaining assets. These eight strategies will be analyzed with six retirement outcome measures over a 30-year retirement period: the average amount whereby spending falls below the minimally acceptable level, the average spending amount, the remaining bequest at the end of the retirement period, the minimum spending amount for any year in the retirement period, a measure of whether spending increases or decreases over time defined as spending in the first year divided by spending in the $30^{\text {th }}$ year, and the value of total spending after accounting for diminishing returns from increased spending for a client with somewhat inflexible spending needs. The model is applied to three client scenarios representing a cross-section of RIIA's client segmentation matrix. It is built using Monte Carlo simulations which reflect current market conditions, so that systematic withdrawals and guaranteed products share compatible underlying assumptions.
\end{abstract}

JEL Codes: C15, D14, G11, G17

Keywords: retirement planning, retirement income modeling

Acknowledgements: Many individuals provided me with useful feedback and discussions about the topics in this article. In particular, I wish to thank Jason Branning, Michael Finke, Francois Gadenne, Michael Kitces, Manish Malhotra, Steve Mitchell, Robert Powell, Dick Purcell, Bob Seawright, Joe Tomlinson, Duncan Williams, and Michael Zwecher. I am grateful for financial support from the Japan Society for the Promotion of Science Grants-in-Aid for Young Scientists (B) \# 23730272. 


\section{Introduction}

A robust evaluation framework is a necessity for assisting clients with the complicated task of choosing a retirement income strategy. As reviewed in Pfau (2012), numerous researchers, planners, and companies are now developing such frameworks. This article seeks to contribute to the growing literature on this topic by presenting the first stages of a new framework guided by the best practices of previous efforts along with some new twists, and constructed with the guiding principles of the Retirement Income Industry Association (RIIA) in mind.

Some of the key features of this framework are as follows. Most importantly, the framework outlined here is compatible with the fundamental goal of retirement planning as described by RIIA, which is to "first build a floor, then expose to upside." It is adaptable to a variety of client circumstances, as inputs (defined as a percentage of retirement date financial wealth) include Social Security benefits, a minimally acceptable retirement spending level as defined by the client, a flooring target defined as the minimal spending needs less Social Security, a desired spending level, and a maximum level in which spending does not rise above in order to preserve funds for later needs.

With variable spending throughout retirement and parameters defining the minimally acceptable spending amount, the desired spending amount, and the maximum spending amount above which funds are saved for future needs, this framework allows for emphasis on both the downside and upside. Spending adapts and it may occasionally fall below the minimal threshold for some income strategies, and clients are able to learn about the likely extent of these shortfalls and assess their importance. At the same time, clients also learn about potential upside, allowing them to consider the tradeoffs with downside protection.

For each income strategy, the distribution of outcomes is provided for measures related to flooring, upside, and bequest. First is the total amount of monetary shortfall below the minimum acceptable spending goal over the retirement period, then the distribution of total spending over the retirement period, and then the distribution of remaining wealth amounts at the end of the retirement period. Additional measures provide more information about how far spending may drop, the direction of spending over the retirement period, and an evaluation measure incorporating the diminishing additional value provided by increasing spending.

Existing frameworks tend to evaluate strategies by looking at a single point in the distribution of outcomes. Whether the risk metric is the failure rate, the average bequest, the expected utility, or even an income frontier comparing failure rates to mean bequests, readers are left to choose a strategy without knowing about the full range of possible 
outcomes. This article takes a different tact, as the entire distribution of outcomes will be shown.

Though not comprehensive, this framework analyzes a wide variety of retirement income strategies, including constant inflation-adjusted withdrawal amounts, a constant withdrawal percentage of remaining assets, a withdrawal percentage based on remaining life expectancy, a more aggressive hybrid withdrawal percentage, inflation-adjusted and fixed single premium immediate annuities, a variable annuity with a guaranteed living withdrawal benefit rider, and a strategy which annuitizes the flooring level to meet basic needs and uses the hybrid withdrawal percentage for remaining assets.

Another feature in this research is that Monte Carlo simulations are calibrated to current market conditions, making the assumptions comparable across the range of strategies. A deficiency found in many existing studies is that payouts for guaranteed products are based on current conditions, while systematic withdrawals are based on historical data averages with dramatically higher stock and bond returns. This study compares strategies with a consistent and realistic set of low fees.

Finally, this research addresses the issue of fixed horizons versus survival probabilities when applying weights to future spending. Both are incorporated into the model, though to preserve space, results will be presented here only for the case of a fixed 30-year retirement period. Using survival probabilities or a short retirement period are both ways to place greater weight on the early part of retirement. This favors strategies providing relatively more early spending and less later spending. Though in some sense retirees should plan to reduce spending as they age to account for the lower probabilities of survival, and this is an implication of weighting spending by survival probabilities, this may be a rather controversial assumption and will be avoided in this article. Nonetheless, the outcome measure showing the distribution of spending in year 1 to spending in year 30 does show the general direction in which spending can be expected to trend during retirement. Clients can then choose among strategies with real spending declines, constant real spending, or even real spending increases in order to best match their preferences.

Though the framework described here is not complete, it provides a starting point. Subsequent refinements can incorporate additional retirement income strategies, market return assumptions, patterns of retirement spending needs and potential health care shocks, and retiree scenarios.

\section{Methodology}


The methodology is detailed in Tables 1, 2, 3, and 4. Table 1 provides the essential details for eight retirement income strategies. These details will not be repeated here. Further assumptions include that withdrawals are made at the start of each year during the 30 -year retirement period. A fixed underlying asset allocation is used throughout the lifecycle (this article considers the case of 70 percent stocks and 30 percent bonds), with annual rebalancing. No account has been made for taxes.

Table 1: Retirement Income Strategies

Withdrawal Strategy Name Abbreviation Description

\begin{tabular}{|c|c|c|c|}
\hline 1) & $\begin{array}{l}\text { Constant Inflation-Adjusted } \\
\text { Amounts }\end{array}$ & Amount & $\begin{array}{l}\text { Spending is defined as a percentage of retirement date financial assets. In } \\
\text { subsequent years, inflation-adjustments keep same spending amount in } \\
\text { real terms for as long as financial wealth remains. Withdrawals fall to zero } \\
\text { when wealth is depleted. }\end{array}$ \\
\hline 2) & Constant Percentage & Percentage & $\begin{array}{l}\text { Retirees withdraw a constant percentage of the remaining portfolio } \\
\text { balance for each year of retirement. Spending amounts will be volatile in } \\
\text { response to portfolio fluctuations. Though spending can never fall to zero, } \\
\text { it can become uncomfortably low. }\end{array}$ \\
\hline 3) & $\begin{array}{l}\text { Percentage Withdrawals } \\
\text { Based on Life Expectancy }\end{array}$ & Life \%age & $\begin{array}{l}\text { This strategy also withdraws a percentage of remaining assets for each } \\
\text { year of retirement. However, this percentage varies with age. It is one } \\
\text { divided by the remaining life expectancy as found in Uniform Lifetimes } \\
\text { (Table III) from the Internal Revenue Service for Required Minimum } \\
\text { Withdrawals (Publication 590). }\end{array}$ \\
\hline 4) & $\begin{array}{l}\text { Hybrid Constant / Life- } \\
\text { Expectancy Percentages } \\
\text { Approach }\end{array}$ & Hybrid \%age & $\begin{array}{l}\text { This strategy combines aspects of ( } 2 \text { ) and ( } 3 \text { ). It is more aggressive than } \\
\text { either as the withdrawal rate is the largest of either the percentage } \\
\text { needed at retirement to meet desired spending, or the percentage based } \\
\text { on remaining life expectancy. }\end{array}$ \\
\hline 5) & $\begin{array}{l}\text { Inflation-adjusted single- } \\
\text { premium immediate annuity }\end{array}$ & Real SPIA & $\begin{array}{l}\text { Financial wealth is used to purchase a } 100 \% \text { Joint and Survivors inflation- } \\
\text { adjusted SPIA. If it is possible to annuitize the maximum spending level } \\
\text { before exhausting wealth, remaining assets are left to grow in a mutual } \\
\text { fund to provide a bequest. Payout rate }=\mathbf{3 . 8 7 5 \%}\end{array}$ \\
\hline 6) & $\begin{array}{l}\text { Fixed Single-premium } \\
\text { immediate annuity }\end{array}$ & Nom SPIA & $\begin{array}{l}\text { Financial wealth is used to purchase a } 100 \% \text { Joint and Survivors fixed SPIA. } \\
\text { If it is possible to annuitize the maximum spending level before exhausting } \\
\text { wealth, remaining assets enter a mutual fund to support additional } \\
\text { withdrawals if inflation causes the real value of the SPIA amount to fall } \\
\text { below the maximum, and to otherwise provide a bequest. Payout rate = } \\
\mathbf{5 . 8 4 \%}\end{array}$ \\
\hline 7) & $\begin{array}{l}\text { Variable annuity with } \\
\text { guaranteed living withdrawal } \\
\text { benefit rider }\end{array}$ & GLWB & $\begin{array}{l}\text { A low cost VA/GLWB, with specifications including a joint withdrawal } \\
\text { payout rate of } 4.5 \% \text {, annuity fees of } 0.6 \% \text {, a guarantee rider of } 0.95 \% \text { of } \\
\text { the benefit base, and an annual step-up feature. }\end{array}$ \\
\hline 8) & Partial Annuitization & FLOOR + HL\% & $\begin{array}{l}\text { An inflation-adjusted SPIA is used to annuitize the full amount of minimal } \\
\text { needs that exceed Social Security. Hybrid percentage withdrawals are } \\
\text { used for discretionary expenses. }\end{array}$ \\
\hline
\end{tabular}

Note: Analysis is for a married couple both aged 65. Administrative fees for stock and bond funds are $0.2 \%$. 
Administrative fees in this study are based on readily available low-cost options. Advisors may introduce additional fees, though these would likely be applied consistently across all strategies. The low-cost fee structure applied here includes a $0.2 \%$ annual administrative fee on stock and bond funds used for systematic withdrawals. For SPIAs, payout rates are taken from Vernon (2012), who used Vanguard's Annuity Access service through the Hueler Income Solutions platform at the start of April 2012. The variable annuity with the GLWB rider is based on the low-cost version provided by Vanguard, with a $0.6 \%$ fee on the variable annuity, and a $0.95 \%$ rider on the benefit base. Payout rates for guaranteed strategies are for a married couple both aged 65 .

Table 2: Retirement Outcome Measures

\begin{tabular}{|c|c|c|}
\hline \multicolumn{2}{|r|}{ Outcome Measure } & Description \\
\hline 1) & $\begin{array}{l}\text { Average Underfunding Below } \\
\text { Minimum Needs }\end{array}$ & $\begin{array}{l}\text { The sum of any spending shortfalls below the minimum acceptable spending level over } \\
\text { each year of the retirement period. }\end{array}$ \\
\hline 2) & Average Spending & The average level of spending over each year of the retirement period. \\
\hline 3) & Bequest & $\begin{array}{l}\text { The remaining financial assets at the end of the retirement period (for fixed horizons) } \\
\text { or a weighted sum of remaining wealth times probability of death at that age (for } \\
\text { survival probabilities) }\end{array}$ \\
\hline 4) & Minimum Spending Amount & The lowest spending amount of any year across the retirement period. \\
\hline 5) & $\begin{array}{l}\text { Direction of Spending } \\
\text { (Year } 1 \text { / Year 30) }\end{array}$ & $\begin{array}{l}\text { Indicates whether the strategy causes retirement spending to decrease, remain the } \\
\text { same, or increase over the retirement period. Values above } 100 \% \text { imply that spending } \\
\text { decreases throughout the retirement period. }\end{array}$ \\
\hline 6) & $\begin{array}{l}\text { Total Spending Value } \\
\text { Spending Flexibility }=5\end{array}$ & $\begin{array}{l}\text { An alternative version of the "average spending" measure which accounts for } \\
\text { diminishing marginal utility value as spending increases. The value of spending across } \\
\text { the retirement period is summed, with each spending amount translated into the value } \\
\text { it provides. Low spending amounts may receive large negative values. With this } \\
\text { spending measure, greater spending is valued, but additional emphasis is placed on } \\
\text { protecting spending from falling too low on the downside. The equation to calculate } \\
\text { spending value is a constant relative risk aversion utility function. }\end{array}$ \\
\hline
\end{tabular}

Note: Outcome measures could be weighted by survival probabilities, or calculated for fixed horizons. All monetary values are tracked in real terms.

Table 2 provides a description of six retirement outcome measures. Full descriptions are in the table. Briefly, these measures cover aspects related to minimal needs and the provision of flooring (the total amount of monetary shortfall below the minimum acceptable spending goal over the retirement period, the minimum spending amount in any one year over the retirement period, and a value of spending measure which emphasizes the harm caused by low spending amounts), to upside spending potential (average spending as well as the previously mentioned spending value measure), and to bequest values. A measure showing whether spending tends to rise, remain the same, or fall in inflation-adjusted terms is also included. The entire distribution of outcomes across the simulations are shown for each measure, which provides greater information about 
the possible outcomes than only a summary statistic like the mean. The results for a fixed 30-year retirement period are described here, though the framework can also incorporate survival probabilities.

Table 3: Assumptions for Real Asset Returns

\begin{tabular}{cccccccc} 
& Arithmetic & Geometric & Standard & & \multicolumn{3}{c}{ Correlation Coefficients } \\
\cline { 6 - 8 } & Mean & Mean & Deviation & Stocks & Bonds & Inflation \\
\hline Stocks & $5.1 \%$ & $3.1 \%$ & $20.0 \%$ & 1 & 0.1 & -0.2 \\
Bonds & $0.3 \%$ & $0.1 \%$ & $7.0 \%$ & 0.1 & 1 & -0.6 \\
Inflation & $2.1 \%$ & $2.0 \%$ & $4.2 \%$ & -0.2 & -0.6 & 1 \\
\hline
\end{tabular}

Equity Premium

$4.8 \%$

Note: Standard deviations and correlation coefficients are based on Stocks, Bonds, Bills, and Inflation data provided by Morningstar and Ibbotson Associates, in which the U.S. S\&P 500 index represents the stock market and intermediate-term U.S. government bonds represent the bond market. The arithmetic mean for bond returns is calibrated to recent TIPS yields. The arithmetic mean for inflation is based on the breakeven inflation rate implied by TIPS and Treasury yields. The arithmetic mean for stock returns is calibrated to allow an equity premium of $4.8 \%$ above the bond return, which is the equity premium for a GDP-weighted portfolio of 19 developed market countries between 1900 and 2010 from the Dimson, Marsh, and Staunton Global Returns Dataset provided by Morningstar and Ibbotson Associates.

Table 3 provides the assumptions for asset markets which guide the underlying 1,000 Monte Carlo simulations. While standard deviations and correlations are calibrated to the U.S. historical data since 1926, the return assumptions are connected to current market conditions rather than historical averages. The arithmetic mean for bond returns is calibrated to recent TIPS yields. The arithmetic mean for inflation is based on the breakeven inflation rate implied by TIPS and Treasury yields. The arithmetic mean for stock returns is calibrated to allow an equity premium of $4.8 \%$ above the bond return, which is the equity premium for a GDP-weighted portfolio of 19 developed market countries between 1900 and 2010 from the Dimson, Marsh, and Staunton Global Returns Dataset provided by Morningstar and Ibbotson Associates.

The framework is built to analyze retirement income strategies for a wide variety of client circumstances. To ease the exposition and conserve space, outcomes will be discussed for a same-aged couple with both members retiring at the age of 65. For the 65-year old couple, three scenarios shown in Table 4 are analyzed in order to provide results for cases from across RIIA's client-segmentation matrix. Though there are nine cells in the RIIA matrix, the three scenarios presented here provide a cross section of the possibilities. These three scenarios are described in the results section. 
Table 4: Three Retiree Scenarios

\begin{tabular}{|c|c|}
\hline 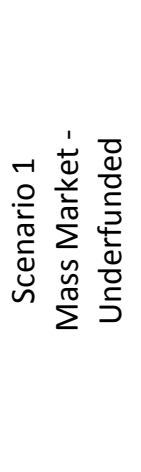 & $\begin{array}{l}\text { Retirement Date Financial Wealth: } \$ 100,000 \\
\text { Desired/Maximum Spending Level } \$ 35,000 \\
(35 \%) \\
\text { Withdrawal Rate: } 15 \% \\
\text { Minimal Needs } \$ 30,000(30 \%) \\
\text { Necessary Flooring: } 10 \% \\
\text { Social Security } \$ 20,000(20 \%)\end{array}$ \\
\hline
\end{tabular}

\begin{tabular}{|c|c|}
\hline 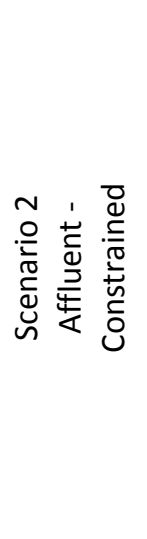 & $\begin{array}{l}\text { Retirement Date Financial Wealth: \$500,000 } \\
\text { Maximum Spending Level \$60,000 (12\%) } \\
\text { Desired Spending Level \$50,000 (10\%) } \\
\quad \text { Withdrawal Rate: } 6 \% \\
\text { Minimal Needs } \$ 35,000(7 \%) \\
\quad \text { Necessary Flooring: } 3 \% \\
\text { Social Security } \$ 20,000(4 \%)\end{array}$ \\
\hline
\end{tabular}

\begin{tabular}{|c|c|}
\hline 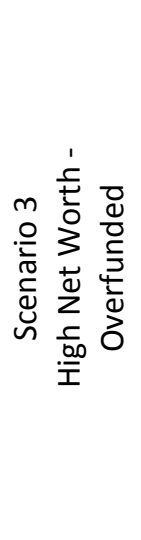 & $\begin{array}{l}\text { Retirement Date Financial Wealth: \$1,000,000 } \\
\text { Maximum Spending Level \$100,000 (10\%) } \\
\text { Desired Spending Level \$65,000 (6.5\%) } \\
\text { Withdrawal Rate: } 3 \% \\
\text { Minimal Needs \$50,000 (5\%) } \\
\text { Necessary Flooring: 1.5\% } \\
\text { Social Security \$35,000 (3.5\%) }\end{array}$ \\
\hline
\end{tabular}

\section{Results}

Scenario 1 Mass Market - Underfunded Client

In Scenario 1 (Mass Market - Underfunded), the couple retires with $\$ 100,000$ of financial assets. Social Security benefits are $\$ 20,000$, representing $20 \%$ of financial assets. The couple views $\$ 30,000$ as their minimally acceptable spending needs over the retirement 
period. This implies that annual flooring of $\$ 10,000$ (10\% of financial assets) above Social Security is needed for the basics. The couple's desired spending level, meanwhile, is $\$ 35,000$ each year. This implies a withdrawal rate from financial assets of $15 \%$ in the first year of retirement to be added to the Social Security benefit. Since the couple is underfunded, they accept that spending above $\$ 35,000$ is not feasible, and so this amount is also the maximum spending level.

\section{$<$ Figure 1 About Here >}

Figure 1 shows the distribution of six outcome measures for the eight retirement income strategies. Often, analysis will provide a summary statistic such as the mean underfunding level for each strategy. Here, the entire distribution of outcomes is shown. The median outcome is identified with a black dash, the $25^{\text {th }}$ to $75^{\text {th }}$ percentiles are identified with a thick dark grey bar, and the entire range of outcomes with a thin lightgrey bar. This provides clients with much more detailed information about potential outcomes than a single summary statistic can show.

For Scenario 1, the initial withdrawal rate is $15 \%$ for the amount, percentage, and hybrid percentage strategies, as this provides the desired spending level for at least the first year of retirement. Spending with the other strategies will be constrained by what is allowable under the spending rule. Initial spending with other strategies are $3.23 \%$ of assets with the life-expectancy based percentage strategy, 3.875\% with the inflation-adjusted SPIA, $5.84 \%$ with the fixed SPIA, $4.5 \%$ with the VA/GLWB, and $3.875 \%$ with the flooring strategy (as all assets must be annuitized without fully meeting the minimal needs).

For the first outcome measure, as minimal needs require a $10 \%$ withdrawal rate, wealth depletion ensures that all strategies result in underfunding from the minimal goal over the 30 -year retirement period in every simulation. Distributions tilt higher for life expectancy, real and nominal SPIAs, GLWBs, and the flooring approach, suggesting that these strategies may appeal to clients emphasizing downside protection for their retirement outcomes. A reoccurring theme throughout this analysis is that the traditional inflation-adjusted withdrawal amount until wealth depletion strategy is rarely attractive by any measure, as its outcome distribution tends to be shifted lower than others.

As for average spending, the nominal SPIA provides the highest median outcome, while the most upside is possible with the life expectancy and GLWB strategies, and downside protection is best provided with real and nominal SPIAs and flooring. As for the remaining wealth after 30 years which may be left as a bequest (or support an even longer retirement period), the only strategies providing any chance to distribute wealth are the life expectancy and GLWB strategies. As for the distribution of lowest spending amounts 
in the worst-case year for each simulation, the real SPIA and flooring approaches perform best.

The next measure, the ratio of spending in the first year of retirement to the $30^{\text {th }}$ year of retirement, shows the direction that spending evolves. The constant amount, constant percentage, and hybrid percentage strategies all start with a $15 \%$ withdrawal rate, ensuring that the wealth remaining for withdrawals after 30 years is either nil or very small. Meanwhile, the life expectancy percentage strategy produces spending power which actually tends to increase over the retirement period, suggestion that further efforts should be made to find middle ground between this and the hybrid strategies. The other four strategies providing guarantees show that spending remains roughly in the same general level from which it started.

Finally, the total spending value approach with spending flexibility of 5 shows lifetime spending weighted by its value for a relatively conservative couple. Upside is valued, but spending below the minimal floor is severely punished with this measure. Again, a case can be made here for the life-expectancy withdrawal percentage or any of the strategies providing guarantees.

This information may be overwhelming, but it provides an overview of the distributions for various important retirement outcome measures which will allow clients and advisors to work together in formulating a retirement income strategy which meets the specific needs and constraints of individual clients. Each strategy provides different outcomes with respect to the downside, the upside, and bequests, and clients can weigh the importance of each criteria to develop a personalized solution.

\section{Scenario 2 Affluent - Constrained Client}

In Scenario 2, the 65-year old couple fits into the RIIA client-segmentation matrix as an affluent, constrained case. Financial assets total $\$ 500,000$, and a withdrawal rate of $6 \%$ is needed to meet the desired spending level of $\$ 50,000$ after accounting for the couple's $\$ 20,000$ Social Security benefit. The couple views their minimal needs as $\$ 35,000$ in annual spending, which requires a flooring level of $\$ 15,000$ (3\% of assets) above Social Security. This couple also feels no need to spend beyond $\$ 60,000$ per year, so withdrawals will not exceed $8 \%$ of the amount of retirement date assets in any year (at most a real $\$ 40,000$ withdrawal is taken in addition to Social Security).

$<$ Figure 2 About Here >

Any of the four systematic withdrawal strategies do result in a notable chance for spending to fall below the minimally acceptable threshold. The real SPIA as well as the 
flooring strategy, which devotes $3 / 3.875=77 \%$ of assets to a real SPIA and then uses the hybrid percentage strategy for remaining wealth, both prevent underfunding. As the fixed SPIA and the GLWB only provide guarantees in nominal terms, underfunding does happen occasionally with these strategies.

As for average spending, the real SPIA and flooring approaches provide consistent average spending across the range of simulations. The fixed SPIA provides the highest median average spending, and the other strategies tend to provide a broader range of outcomes with both upside and downside.

The results for bequests are a mirror image of the results for average underfunding. The systemetic withdrawal strategies all provide more chance for a bequest, followed by the GLWB and flooring strategies. Since all assets must be annuitized in an effort to meet the desired spending level, neither the real or fixed SPIA provides any bequest.

For the minimum spending amount over 30 years, the real SPIA provides the strongest outcome, following by flooring. The constant amount strategy results in the lowest spending in the median case, but also the highest probability to keep spending at the desired level for the entirety of retirement. As for the direction of spending, all strategies tend to show a decline between the first and $30^{\text {th }}$ years. Finally, when spending amounts are weighted to reflect diminishing value as spending increases, a strong case can be made for any of the four strategies providing guarantees.

\section{Scenario 3 High Net Worth - Overfunded Client}

In Scenario 3, the 65-year old couple holds retirement date financial assets worth $\$ 1$ million. Social Security provides $\$ 35,000$, and the couple's minimal spending needs are $\$ 50,000$. Flooring above Social Security to meet these needs is $\$ 15,000$, or $1.5 \%$ of retirement date assets. The couple's desired spending level is $\$ 65,000$, so their withdrawal rate to meet their desired spending after accounting for Social Security is $3 \%$. Their maximum spending level is $\$ 100,000$, so that, in real terms, the couple will never withdraw more than $\$ 65,000$ from their portfolio in any single year.

\section{$<$ Figure 3 About Here >}

The flooring strategy in Scenario 3 devotes $1.5 / 3.875=39 \%$ of assets to building a floor above Social Security in order to meets basic needs. The patterns for these retirement outcome measures are similar to Scenario 2. Systematic withdrawals may result in underfunding below minimal needs, while also providing the best chance to leave a bequest. The flooring strategy does allow for some chance to bequeath assets while also supporting the minimum floor, as does the GLWB strategy. The median average 
spending outcome is the highest with the nominal SPIA, and the worst-case average spending is the highest with the real SPIA. The real SPIA also supports the highest minimum spending amount over the 30 year period. As for the direction of spending, the life-expectancy percentage, hybrid percentage, and flooring approaches all result in a gradual spending increase in the median case, while the other strategies generally lead to spending declines. When avoiding downside is given higher weight in the total spending value measure, again the strategies with guarantees all outperform the systematic withdrawal strategies.

\section{Conclusion}

Further refinements are needed to include a broader range of retirement income strategies, including optimization for the Social Security claiming decision, bond ladders and time segmentation approaches, delayed or laddered annuity purchases, deferred income annuities and various other products. Nevertheless, the approach described provides the initial stages of a new framework which can inform advisors and clients about the benefits and disadvantages of various retirement income strategies.

\section{References}

Pfau, Wade D. 2012. "Choosing a Retirement Income Strategy: Outcome Measures and Best Practices." Unpublished draft.

Vernon, Steve. 2012. "Retirement Income Scorecard: Immediate Annuities." CBS News. (April 4). http://www.cbsnews.com/8301-505146_162-57408049/retirement-incomescorecard-immediate-annuities/ 
Figure 1

Distribution of Retirement Outcome Measures

Scenario 1: Mass Market - Underfunded, 70\% Stocks
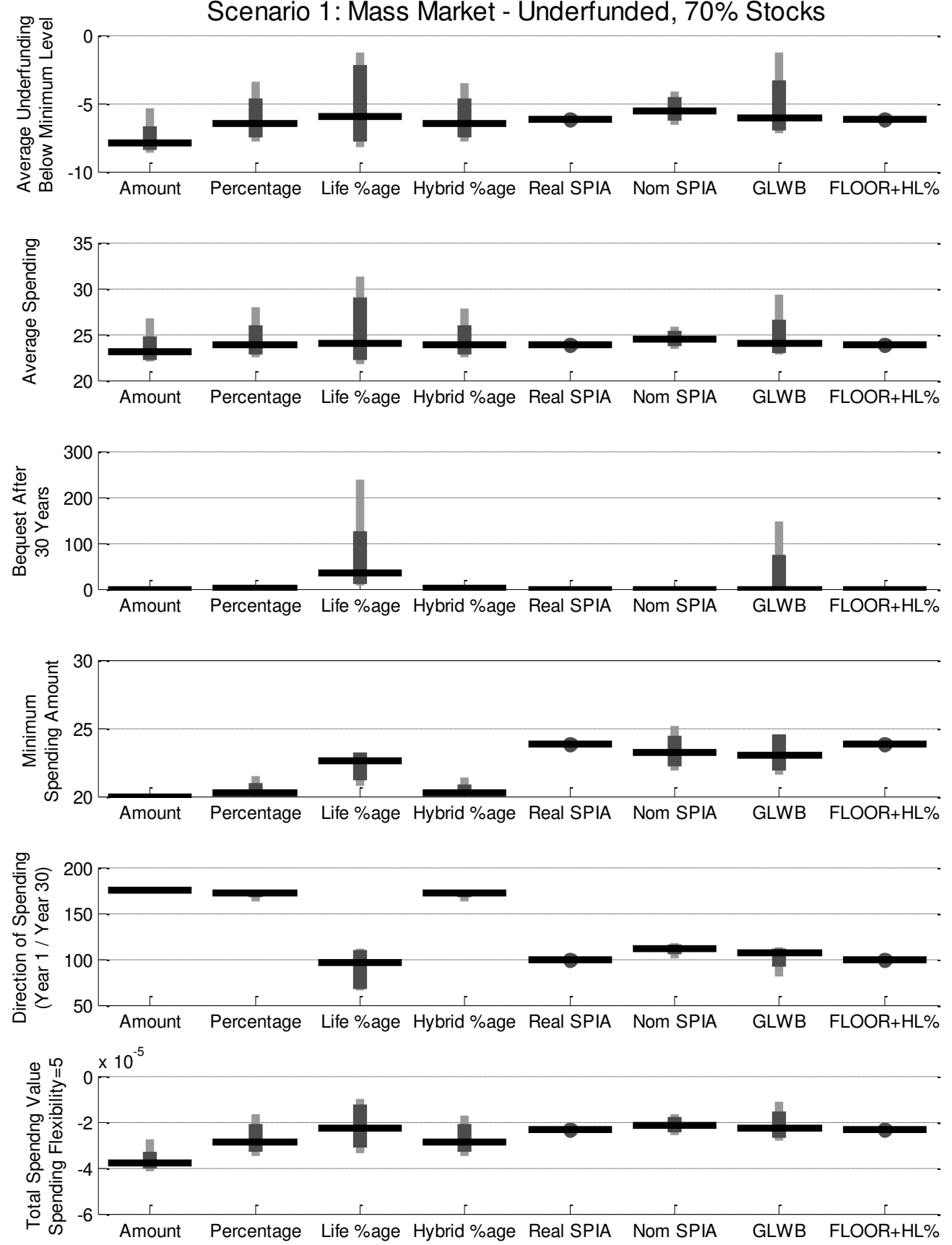
Figure 2

Distribution of Retirement Outcome Measures

Scenario 2: Affluent - Constrained, 70\% Stocks
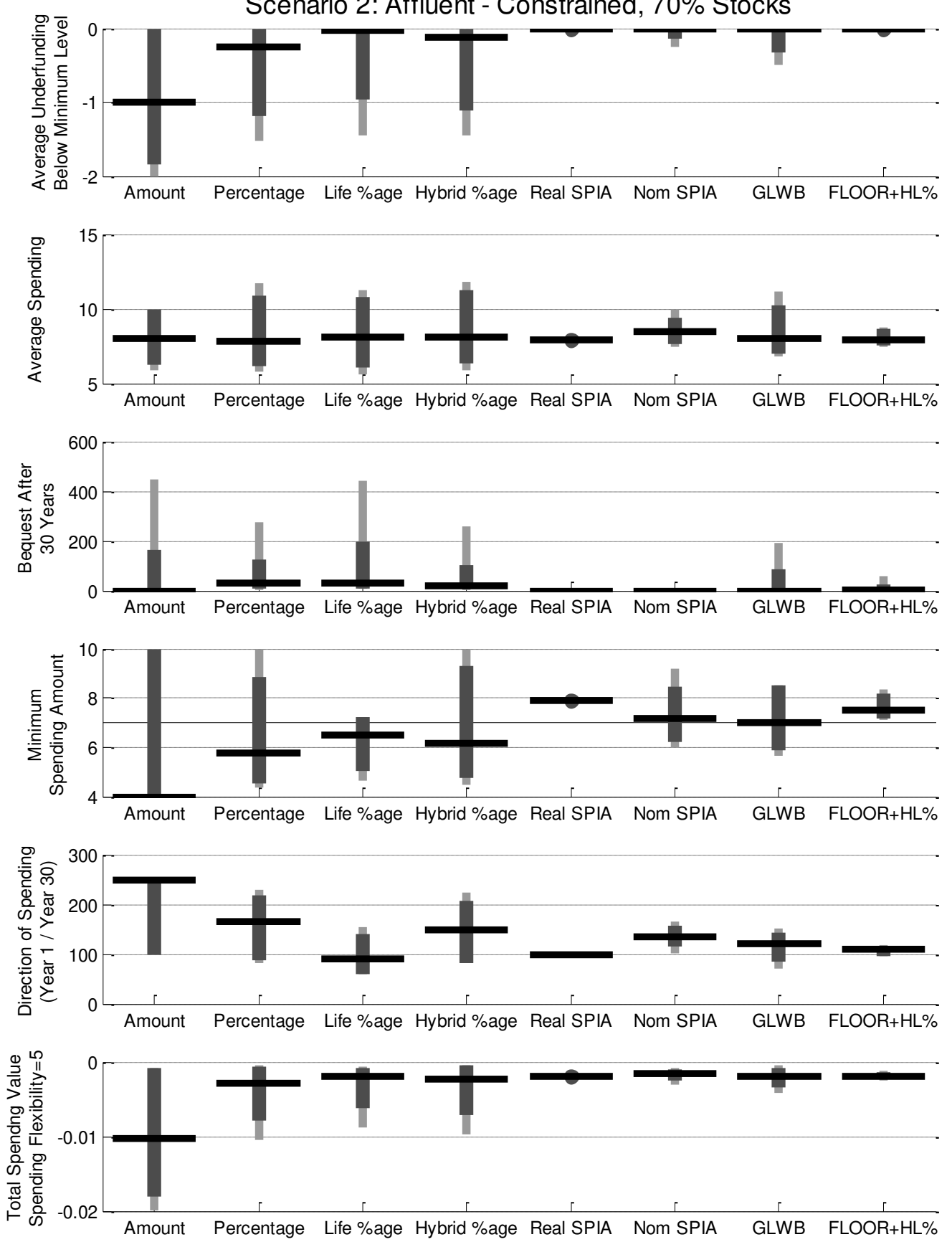
Figure 3

Distribution of Retirement Outcome Measures

Scenario 3: High Net Worth - Overfunded, 70\% Stocks
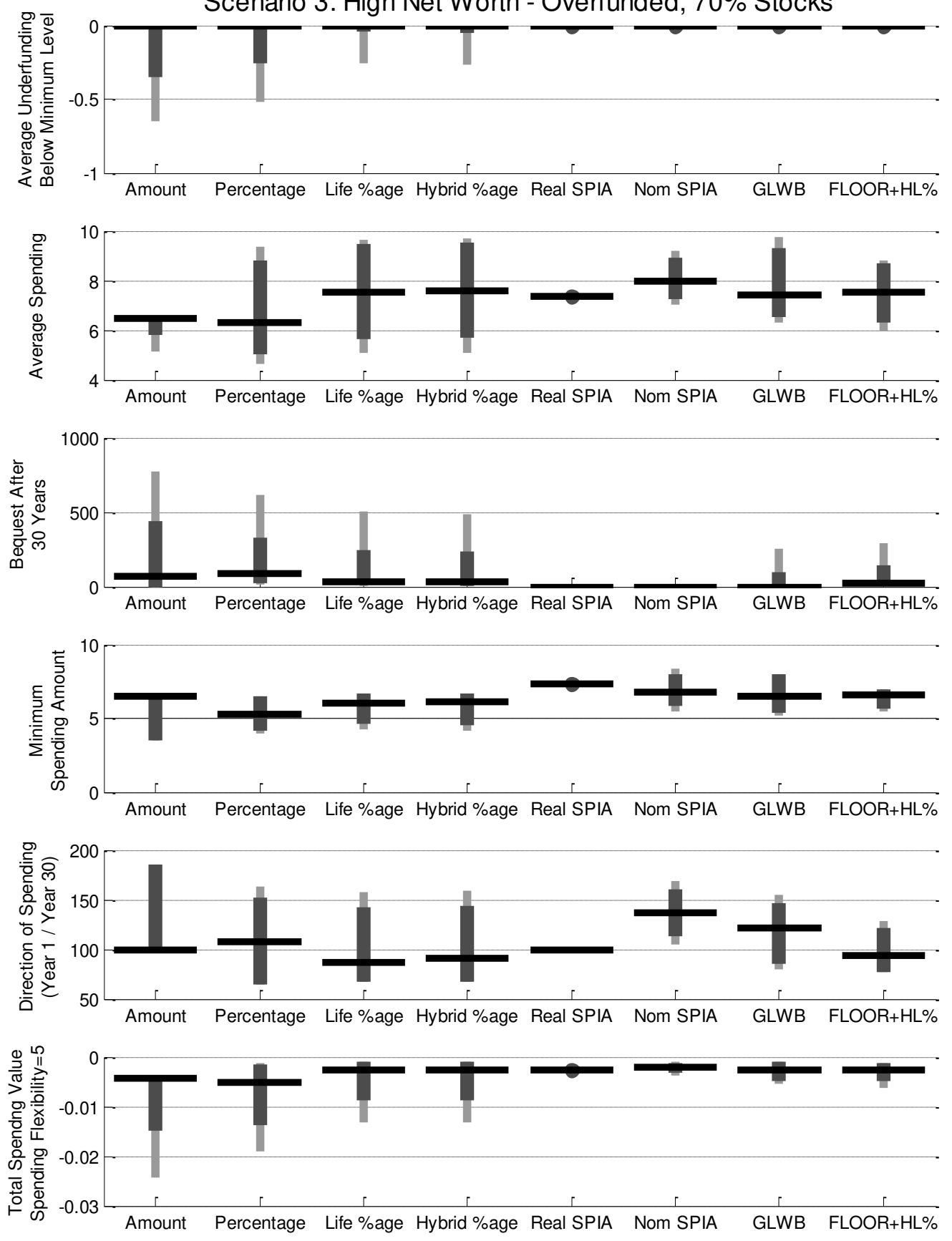